\title{
Health Related Quality of Life among the Coronary Heart Disease Patients
}

\author{
Sabita Mandal' ${ }^{1}$, Shantonu Kumar Ghosh ${ }^{2}$, Mahbubur Rahman ${ }^{2}$, Alpana Majumder ${ }^{3}$, Redoy \\ Ranjan ${ }^{4}$, Dipannita Adhikary4, Kamrul Hasan², Md. Ziaul Islam ${ }^{5}$, Asit Baran Adhikary ${ }^{4}$ \\ ${ }^{1}$ Department of Community Medicine, Shaheed Suhrawardy Medical College, Dhaka, ${ }^{2}$ Department of \\ Cardiac Surgery, NICVD, Dhaka, ${ }^{3}$ National Center for Control of Rheumatic Fever and Heart \\ Diseases, Dhaka, ${ }^{4}$ Department of Cardiac Surgery, Bangabandhu Sheikh Mujib Medical University, \\ Dhaka, ${ }^{5}$ Department of Occupational and Environmental Health, National Institute of Preventive and \\ Social Medicine, Dhaka.
}

Key Words : Coronary Heart Disease, Health Related Quality of Life, WHOQOL-BREF.

\begin{abstract}
:
Background: Coronary heart disease (CHD) is one of the leading causes of death in both developed and developing countries including Bangladesh. CHD endanger not only physical health but also psychological, environmental and social health of the patients seriously and many of them live without hope to improve. Thus evaluation of health related quality of life of such patients is very important.
\end{abstract}

Methods: This descriptive cross sectional study was conducted among 217 CHD patients at the National Institute of Cardiovascular Diseases (NICVD), Sher-e-Bangla Nagar, Dhaka, during the period from January to December 2013. The study intended to assess their health related quality of life in terms of general health, physical health, psychological health, social relationship and environmental conditions. Data were collected by a semi-structured questionnaire based on WHOQOLBREF (26) scale.

Results: Regarding level of quality of life and general health, majority (51.2\%) had "average" quality of life while in respect of physical health, most (89.9\%) of the patients had "average" quality of health. Regarding psychological health, majority (72.8\%) had "average" quality while regarding social relationship, majority (53.9\%) had "average" quality and by environmental conditions, majority $(64.1 \%)$ had "average" quality. Overall health related quality of life by age of the CHD patients was statistically significant as most (391.3\%) of the CHD patients with age 30-49 years had "average" while majority (53.3\%) of the elderly (65-75 years) had "poor" quality of life [ $\left.\chi^{2}{ }_{(4)}=28.42, p<0.01\right]$. Overall quality of life and general health was "average" among most (31.3\%) of the middle aged patients while it was "poor" among majority (53.3\%) of the elderly patients and this variation was statistically significant $\left[\chi^{2}{ }_{(10)}=35.89, p<0.01\right]$. Overall quality of life and general health was "average" among most (91.3\%) of the middle aged patients while it was "poor" among majority (53.3\%) of the elderly patients and this variation was statistically significant $\left(\chi^{2}{ }_{(4)}, p<0.01\right)$. All of the retired patients had "average" and most (94.0\%) of the service-holder had "average" physical health.

Conclusion: The study recommends effective measures to improve the overall health related quality of life of the CHD patients in the context of Bangladesh.

(Cardiovasc. j. 2016; 9(1): 43-48)

\section{Introduction:}

Chronic diseases endanger not only physical health but also psychological and social health of patient seriously and many of them live without hope to improve. Generally, cardiac disease is among such chronic diseases. Coronary artery disease is the most common cardiovascular disease. It is most prevalent among the middle aged and elderly in most developing countries. ${ }^{1}$ According to the
British Medical Bulletin published in 2009 cardiovascular disease is the leading cause of death worldwide in both male (31.5\%) and female (26.8\%) group. According to "world health rankingBangladesh Health Profile 2010" coronary heart disease cause $17.11 \%$ of all deaths in Bangladesh and 1.0 person per 1000 population are at risk. Bangladesh ranks $25^{\text {th }}$ position in the world in respect to cause of death due to coronary artery 
disease. ${ }^{2}$ Due to increasing rates of urbanization and adoption of "western" culture, the prevalence of CHD in developing countries like Bangladesh is rapidly increasing. Total number of patients who die due to coronary heart disease every year worldwide is almost 76 million. But $40 \%$ death can be prevented by controlling risk factors and life expectancy can be increased 10 years globally. In the early $20^{\text {th }}$ century, coronary heart disease ranked as $4^{\text {th }}$ as cause of death in USA. At present it is ranked as the $1^{\text {st }}$ as cause of global death. A study in India found the prevalence of CHD as 25.4 and 18.3 per 1000 males and females respectively. ${ }^{3}$ It is expected that $82 \%$ of the future increase in coronary heart disease mortality will occur in developing countries. Of all coronary heart disease patients who die within 28 days after the onset of symptoms, about two-thirds die before reaching hospital. Bangladesh is one of the developing countries whose both incidence and prevalence of coronary heart disease has been increasing gradually and if necessary steps are not taken it is feared that by next 10-15 years the number of patients will increase dramatically. According to the latest WHO data published in April 2011 coronary heart disease deaths in Bangladesh reached 163,769 or $17.11 \%$ of total deaths. Bangladeshi people, as other South Asians, have high susceptibility to coronary heart disease (CHD) but population-based data are lacking in Bangladesh.

The World Health Organization (WHO) defines Quality of life as an individual's perception of their position in life in the context of the culture and value systems in which they live and in relation to their goals, expectations, standards and concerns. It is a broad ranging concept affected in a complex way by the person's physical health, psychological state, personal beliefs, social relationships and their relationship to salient features of their environment. A number of factors contribute including good health, a secure social and occupational environment, financial security, spiritually, self-confidence and strong supportive relationships. These factors are interrelated with each of the others. For instance, a patient will often be able to deal with an illness better if she/ he have good family support, a strong faith and the financial ability to acquire nourishing food, shelter and treatment. Health-related quality of life can be considered as that part of a person's overall quality that is determined primarily by their health status which can be influenced by clinical interventions. ${ }^{4}$

The World Health Organization (WHO), with the aid of 15 collaborating centers around the world, has therefore developed two instruments of life (the WHOQOL-100 and the WHOQOL-BREF). In this study the WHOQOL-BREF 26 was used for measuring quality of life. It is important to objectively assess CHD progression and the efficacy of treatment through diagnostic test but subjective data such as health related-quality of life (HRQOL)) questionnaires can also provide useful information. HRQOL may reveal important information not gained from the clinical data.

\section{Methods:}

This cross-sectional study was conducted at the medical and surgical in-patient and out-patient departments of the National Institute of Cardiovascular Diseases (NICVD), Sher-e-Bangla Nagar, Dhaka. in which total 217 diagnosed CHD patients were enrolled. Data was collected by using semistructured questionnaires based on WHOQOLBREF scale and a checklist by face-to -face interview and reviewing medical records of the CHD patients. After collection, the data were checked and cleaned. Analysis was performed using the latest available version of SPSS software. Data was presented in frequency tables, bar, pie and scatter diagram as per need. For inferential statistics, chi-square test was done to compare association between health related quality of life and socio-demographic characteristics of the patients.

\section{Results:}

In this study out of $217 \mathrm{CHD}$ patients, $94.0 \%$ was male and $6.0 \%$ were female patients. Mean $(+\mathrm{SD})$ age of patients was $53.59( \pm 9.12)$ years. Majority i.e. $54.4 \%$ patients were within 50 to 64 years had "average" quality of life. On the other hand, with the age group 65-75 years (53.3\%) had "poor" overall quality of life. All the enrolled patients (217) in this study were married. Among the patients, $24.9 \%$ were graduate, $23.5 \%$ had secondary education, $20.3 \%$ had higher secondary education, $6.0 \%$ were Illiterate. Majority of graduate and secondary had "average" quality of life. Majority 
of primary had "poor" quality of life. Among all the patients, businessmen, service holder and farmer was $35.9 \%, 30.9 \%$ and $17.5 \%$ respectively. Only the day-labors had "poor" quality of life. The average monthly family income with standard deviation was Tk. 21032.26 ( \pm 8396.09$)$. Majority i.e. $39.6 \%$ patients had monthly family income of Tk. 10001 to $20000,36.4 \%$ had 20001 to 30000 . Patients with monthly income Tk. 5000-10000 had "poor" quality of life and the rest groups had "average".

Table-I

Distribution of the patients by overall quality of life.

\begin{tabular}{lcc}
\hline Level of Overall Quality of Life & Frequency & Percentage \\
\hline Poor & 26 & 12.0 \\
Neither poor nor good & 83 & 38.2 \\
Good & 93 & 42.9 \\
Very good & 15 & 6.9 \\
\hline Total & 217 & 100.0 \\
\hline
\end{tabular}

Table-II

Association between overall health related quality of life and age group.

\begin{tabular}{lcccc}
\hline Age group(Yrs.) & \multicolumn{3}{c}{$\begin{array}{c}\text { Distribution of overall health } \\
\text { related quality of life }\end{array}$} & Totalf (\%) \\
\cline { 2 - 4 } & Good f (\%) & Average f (\%) & Poor f (\%) & \\
\hline $30-49$ & $01(1.4 \%)$ & $63(91.3 \%)$ & $05(7.2 \%)$ & $69(100.0 \%)$ \\
$50-64$ & $0(0.0 \%)$ & $93(78.8 \%)$ & $25(21.2 \%)$ & $118(100.0 \%)$ \\
$65-75$ & $0(0.0 \%)$ & $14(46.7 \%)$ & $16(53.3 \%)$ & $30(100.0 \%)$ \\
\hline Total & $01(0.5 \%)$ & $170(78.3)$ & $46(21.2 \%)$ & $217(100.0 \%)$ \\
\hline
\end{tabular}

Significance $\quad \mathrm{X}_{(4)}^{2}=28.421, \mathrm{p}=.000$

\section{Table-III}

Association between overall health related quality of life and education of the patients.

\begin{tabular}{lcccc}
\hline Education & \multicolumn{3}{c}{$\begin{array}{c}\text { Distribution of overall health } \\
\text { related quality of life }\end{array}$} & Total f (\%) \\
\cline { 2 - 4 } & Good f (\%) & Average f (\%) & Poor f (\%) & \\
\hline Primary & $0(0.0 \%)$ & $09(32.1 \%)$ & $19(67.9 \%)$ & $28(100.0 \%)$ \\
Secondary & $0(0.0 \%)$ & $43(84.3 \%)$ & $08(15.7 \%)$ & $51(100.0 \%)$ \\
Highersecondary & $0(0.0 \%)$ & $41(93.2 \%)$ & $03(6.8 \%)$ & $44(100.0 \%)$ \\
Graduate & $01(1.9 \%)$ & $41(75.9 \%)$ & $12(22.2 \%)$ & $54(100.0 \%)$ \\
Masters & $0(0.0 \%)$ & $27(100.0 \%)$ & $0(0.0 \%)$ & $27(100.0 \%)$ \\
Illiterate & $0(0.0 \%)$ & $09(69.2 \%)$ & $04(30.8 \%)$ & $13(100.0 \%)$ \\
\hline Total & $01(0.5 \%)$ & $170(78.3 \%)$ & $46(21.2 \%)$ & $217(100.0 \%)$ \\
\hline Significance & $\mathrm{X}^{2}{ }_{(10)}=54.002, \mathrm{p}=0.000$ & & &
\end{tabular}


Table-IV

Association between overall health related quality of life andoccupation of the patients.

\begin{tabular}{lcccc}
\hline Occupation & \multicolumn{3}{c}{$\begin{array}{c}\text { Distribution of overall health } \\
\text { related quality of life }\end{array}$} & Totalf (\%) \\
\cline { 2 - 5 } & Good f(\%) & Average f (\%) & Poor f (\%) & \\
\hline Service holder & $0(0.0 \%)$ & $61(91.0 \%)$ & $06(9.0 \%)$ & $67(100.0 \%)$ \\
Business & $01(1.3 \%)$ & $66(84.6 \%)$ & $11(14.1 \%)$ & $78(100.0 \%)$ \\
Day-labor & $0(0.0 \%)$ & $04(28.6 \%)$ & $10(71.4 \%)$ & $14(100.0 \%)$ \\
Agricultural-worker0 $0(0.0 \%)$ & $27(71.1 \%)$ & $11(28.9 \%)$ & $38(100.0 \%)$ \\
Housewife & $0(0.0 \%)$ & $04(50.0 \%)$ & $04(50.0 \%)$ & $08(100.0 \%)$ \\
Retired & $0(0.0 \%)$ & $08(66.7 \%)$ & $04(33.3 \%)$ & $12(100.0 \%)$ \\
Total & $01(0.5 \%)$ & $170(78.3 \%)$ & $46(21.2 \%)$ & $217(100.0 \%)$ \\
\hline
\end{tabular}

Significance $\mathrm{X}_{(10)}=37.562, \mathrm{p}=0.000$

Table-V

Association between overall health related quality of life and monthly family income.

\begin{tabular}{lcccc}
\hline Income group & \multicolumn{3}{c}{$\begin{array}{c}\text { Distribution of overall health } \\
\text { related quality of life }\end{array}$} & Totalf (\%) \\
\cline { 2 - 4 } & Goodf (\%) & Averagef (\%) & Poorf (\%) & \\
\hline $5000-10000$ & $0(0.0 \%)$ & $16(50.0 \%)$ & $16(50.0 \%)$ & $32(100.0 \%)$ \\
$10001-20000$ & $0(0.0 \%)$ & $64(74.4 \%)$ & $22(25.6 \%)$ & $86(100.0 \%)$ \\
$20001-30000$ & $01(1.3 \%)$ & $73(92.4 \%)$ & $05(6.3 \%)$ & $79(100.0 \%)$ \\
$30001-50000$ & $0(0.0 \%)$ & $17(85.0 \%)$ & $03(15.0 \%)$ & $20(100.0 \%)$ \\
\hline Total & $01(0.5 \%)$ & $170(78.3 \%)$ & $46(21.2 \%)$ & $217(100.0 \%)$ \\
\hline
\end{tabular}

Significance $\mathrm{X}^{2}{ }_{(6)}=29.208, \mathrm{p}=0.000$

This study findings revealed that most i.e. $20.41 \%$ patients first felt mid chest pain with vomiting, $17.20 \%$ complaint heart burn, $14.68 \%$ felt tightness of the chest, $12.61 \%$ patients complaint respiratory distress, $11.23 \%$ felt choking of the jaw and $5.96 \%$ patients complaint palpitation. After diagnosis of $\mathrm{CHD}$, majority i.e. $65.0 \% \mathrm{CHD}$ patients received medical treatment and rest $35.0 \%$ patients received surgical treatment. Almost all the patients were suffering from other diseases like hypertension (53.8\%) with diabetes mellitus (28.6\%), chronic obstructive pulmonary disease (COPD) (14.1\%) and valvular heart disease 12 (3.5\%). The study found that $42.9 \%$ patients rated their quality of life as "good" followed by $38.2 \%$ rated as "neither poor nor good", $12.0 \%$ rated as "poor" and rest $6.9 \%$ patients rated their quality of life as "very good". Among all the patients in this study, majority i.e. $51.2 \%$ patients had "average" quality of life and general health, 35.0\% had "good" and rest $13.8 \%$ had "poor" quality of life. $41.0 \%$ patients were "satisfied" with their sleep, 33.6\% were "neither satisfied nor dissatisfied", $20.3 \%$ were "dissatisfied" with their sleep. $46.5 \%$ were "neither satisfied nor dissatisfied", $38.7 \%$ were "satisfied", $14.8 \%$ were "dissatisfied" with their working capacity. $56.2 \%$ patients felt that life is meaningful "very much", 24.9\% felt "an extreme amount", $16.1 \%$ felt "a moderate amount" meaningful. Out of all the patients, $44.7 \%$ felt negative feelings "very often", $36.4 \%$ felt "quite often", $12.4 \%$ felt "seldom". Regarding personal relationship, $52.5 \%$ patients were "satisfied", 32.7\% were "neither satisfied nor dissatisfied", $7.8 \%$ were "dissatisfied". $31.3 \%$ were "satisfied" about their sex- life, $30.9 \%$ were "neither satisfied nor dissatisfied", $27.2 \%$ were "dissatisfied" with their sex life. Among the patients, $45.6 \%$ were "satisfied", 26.3\% were "neither satisfied nor 
dissatisfied", $22.6 \%$ were "very satisfied" about their access to health services. Most of them i.e. $89.9 \%$ had "average" quality and rest $10.1 \%$ had "poor" quality of physical health. Out of all the patients, $72.8 \%$ had "average" quality of psychological health, $24.0 \%$ had "poor" and rest $3.2 \%$ patients had "good" quality of psychological health. 53.9\% had "average" level of social relationship, 27.6\% had "poor" and rest $18.4 \%$ patients had "good" level of social relationship.Most i.e. $64.1 \%$ had "average", 35.5\% had "poor" and rest $0.5 \%$ had "good" level of environmental health. Among the patients, most i.e. $79.3 \%$ had "average", $20.2 \%$ had "poor" and rest $0.5 \%$ had "good" level of total health score.

\section{Discussion:}

This descriptive cross-sectional study was carried out among the coronary heart disease patients attending at the out-patient department and inpatients departments of National Institute of Cardiovascular Diseases, Dhaka, Bangladesh, a specialized hospital at the national level, based on socio- demographic characteristics and WHOQOLBREF (26Questionnaire) scale. The objective of this study was to assess the level of HRQOL in terms of overall quality of life and general health and four domains: 1) Physical health domain, 2) Psychological health domain, 3) Environmental health domain and 4) Social relationship domain to identify socio- demographic characteristics of them and to assess the association between health related quality of life and pattern of coronary heart disease. In this study, a total of two hundred and seventeen (217) patients were enrolled. This study showed that out of all patients, majority that is $204(94.0 \%)$ were male and $13(6.0 \%)$ were female by sex. Hayes et al. describes a study where CHD was more in males (56\%) than in females (44\%) because it is said and well known that CHD affect males more than females especially before the age of 60 years. ${ }^{5}$ In this study, average age of coronary heart disease patients were $53.59( \pm 9.12)$ years. Most of the patients were within 50 to 64 years. Grandeet al showed that their average age was 58.6 years (most cases were between 46 to 65 years old). ${ }^{6}$ In our country perspective, 50 to 64 years age is highly vulnerable period to develop CHD, more often it seems to be responsible for behavioral and physiological factors. Behavioral factors include reduced physical activity; a poor diet high in saturated fats; smoking and stress followed by atheroma, plaques of cholesterol build up in the coronary arteries and develop ischemia or myocardial infarction (MI). The physical factors associated with CHD include hypertension (HTN), increased plasma insulin (DM) and increased plasma cholesterol.

From this study, we found that educated persons are more conscious about their health than illiterate. Tofighi et al. showed a study in Iran hospital that disturbed HRQOL of CHD was increased with older age, was reduced with higher levels of education and income, and was elevated among women than men. ${ }^{7}$ In this study we found that service holders and businessmen were always in sedentary life style, taken high cholesterol diet with reduced physical exercise, so they were more affected by CHD whereas day laborer, farmer were hard worker. Also housewives were hard worker, so they were less affected. Among the patients, majority patient's monthly family income was Tk. 10001 to 20000. In a study, Davoodi et al. found that most of the patients were from middle socioeconomic status and followed by low socio-economic status patients. ${ }^{8}$ In this study, we found that initially majority patients received their early treatment from Govt. hospitals, most of them were diagnosed within 1 to 30 days. The delay in diagnosis occurs because of the fact that the most of the symptoms that is chest pain or discomfort or (heart burn) of CHD are similar and maximum patients received antacid, omeprazole and painkiller at first. Diagnostic procedures like exercise tolerance test (ETT), coronary angiogram (CAG), CT- angiogram, percutaneous transluminal coronary intervention (PCI) and primary PCI are not available uniformly throughout the country. After diagnosis of coronary heart disease, majority that is $65.0 \%$ CHD patients received medical treatment and rest $35.0 \%$ patients received surgical treatment. Bangladesh is a developing country and population is very high. But patients are benefitted a lot from Govt. hospitals by receiving medical treatment like PTCA and surgical treatment by CABG. Patients who were suffering from other diseases like hypertension (53.8\%) with diabetes mellitus (28.6\%), more affected to CHD. In a study Ghosh described $46.0 \%$ patients were hypertensive and $42.0 \%$ were diabetic. ${ }^{9}$ Most researchers agree that modifying these risk factors can influence the control and decrease the affection by CHD. So urgent measures should be taken by health personnel and policy makers to modify lifestyles including alteration in diet, calories, lipid and cholesterol intake, increase in physical activity and decrease in psychological stress. 
Among all the patients in this study, it was found that majority were "satisfied" about their current health status. In a study in Sweden 2013, Baumeister et al. showed that the CHD patients had significantly lower scores in life style. ${ }^{10}$ Among all the patients in this study, majority patients had "average" quality of life and general health. A study was conducted on "distribution of patient satisfaction about CHD intervention with focused on "WHOQOL-BREF" where found that 49.8\% patients were satisfied with their quality of life in general health after PCI.

In another study, Lee et al. found an association between HRQOL and physical activity, with better HRQOL outcomes in physically active persons ${ }^{11}$. Similarly, Skovoda et al. reported a higher HRQOL in coronary patients who are active or exercise regularly, compared to sedentary patients. ${ }^{12}$ In a study, Ho et al. found that age and educational level were significantly associated with HRQOL, with men having a better self-perceived HRQOL compared to women, younger patients scoring higher on physical health and overall well-being, and those with lower education levels having worse HRQOL compared to those with higher levels of education. ${ }^{13}$

\section{Conclusion:}

The study revealed that overall quality of life and general health, majority of the patients had "average" level of quality of life. The association between overall quality of life \& general health and age (30-49 years) of the patients was statistically highly significant. It was found those highly qualified patients recognized their symptoms rapidly and made decision quickly to take specific health care without or short delay and majority of them were found in average quality of life. The level of psychological health, physical health and environmental health of majority patients in this study was found "average". Most of the retired patients had "average" and most service-holder had "average" physical health. The study findings recommend for need-based health care measures and interventions in respect of physical, psychological, social and environmental dimensions of health to improve the overall health related quality of life of the coronary heart disease patients in the context of Bangladesh.

\section{Conflict of Interest - None.}

\section{Reference:}

1. McMurray J, Stewar S. Epidemiology, etiology, and prognosis of heart failure. Heart .2000; 83(5):596-602.
2. World Health Organization, World health rankings (2011)- Health Profile: Bangladesh, Geneva, Switzerland; World Health Organization; May, 2014. Available at: http://www.worldlifeexpectancy.com/ country-health-profile/bangladesh[Accessed 18 September, 2015].

3. World Health Organization, Division of Mental Health and Prevention of Substance Abuse,WHOQOL measuring Quality of life, Geneva, Switzerland; World Health Organization; 1997.

4. VanManen J, Bindels P, Dekker F, Bottema B, Vander J, Zee J, et al. The fluence of COPD on health-related quality of life independent of the influence of co morbidity. J Clin Epidemiol 2003; 56(12): 1177-1184.

5. Hayes D, GreenlundK, Denny C, Neyer J, Croft J, Keenan NL. Racial/ethnic and socioeconomic disparities in health-related quality of life among people with coronary heart disease, 2007. Prev Chronic Dis 2011; 8(4): A78-A82.

6. Grande M, Elliott P, Murphy B, Worcester M, Higgins R, Ernest C, et al. Health related quality of life trajectories and predictors following coronary artery bypass surgery. Health and Quality of Life Outcomes, 2006; 4: 49-54. Available at: http://www.hqlo.com/ content/4/1/49 [Accessed 12 September, 2015].

7. Tofighi S, Ahmad-Kiadaliri A, Sadeghifar J, Raadabadi M, Mamikhani J. Health related quality of life among patients with coronary artery disease: A post-treatment follow-up study in Iran. Cardiol Res Pract 2012; 2012: 973-978.

8. Davoodi S, Sheikhvatan M, Karimi A, Ahmadi S, Goodarzynejad H, Fathollahi M. Outcomes and longterm quality of life of patients with severe left ventricular dysfunction who underwent coronary artery bypass surgery. Gen Thorac Cardiovasc Surg 2012; 60(4): 202-212.

9. Ghosh SK. Health related quality of life after coronary artery bypass surgery [unpublished thesis]. Bangabandhu Sheikh Mujib Medical University; 2016.

10. Baumeister H, Hutter N, Bengel J, Harter M. Quality of life in medically ill persons with comorbid mental disorders: A systematic review and meta-analysis. Psychother Psychosom 2011; 80(5): 275-286.

11. Lee G, Coronary Artery Disease and Quality of Life In: Stone J, Blouin M. Editors. International Encyclopedia of Rehabilitation, Buffalo, NY: CIRRIE; 2010. Available at: http://cirrie.buffalo.edu/encyclopedia/en/article/134/ [Accessed 23 August, 2015]

12. Skovoda Z, VanDijk J, Nagyova I, Rosenberger J, Ondusova D, Studencan M, et al. Psychological factors of coronary heart disease and quality of life among Roma coronary patients: a study matched by socioeconomic position. Int J Public Health 2010;55: 373-380.

13. Ho S, Ting C, Das S, Loo C,Rohayu A, Khor S, et al. The quality of life among coronary heart disease patients at a teaching hospital. Clin Ter 2011; 162(3): 217-222. 